\title{
Is Mobile Email Functional or Dysfunctional? Two Perspectives on Mobile Email Usage
}

\section{Catherine A. Middleton}

Ryerson University

\section{Wendy Cukier}

Ryerson University

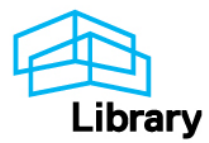




\title{
Is Mobile Email Functional or Dysfunctional? Two Perspectives on Mobile Email Usage
}

\author{
Catherine A. Middleton* \\ Wendy Cukier \\ School of Information Technology Management \\ Ryerson University \\ 350 Victoria Street \\ Toronto, ON, M5B 2K3 \\ Canada
}

*Corresponding author: Telephone: +1 4169795000 x. 7923, cmiddlet@ryerson.ca

This is a pre-print version of this paper. The published version is available in the European Journal of Information Systems:

Middleton, C. A., \& Cukier, W. (2006). Is Mobile Email Functional or Dysfunctional? Two Perspectives on Mobile Email Usage. European Journal of Information Systems, 15(3), 252-260.

http://www.palgrave-journals.com/ejis/journal/v15/n3/abs/3000614a.html 


\begin{abstract}
This paper offers a study of contradiction in the usage of mobile email. Using qualitative data, the paper identifies mobile email usage patterns that are dangerous, distracting, anti-social and that infringe on work-life boundaries. Mobile email users were forthcoming in describing these dysfunctional usage patterns, but they made a convincing argument that their mobile devices are highly functional and allow them to be efficient, to multitask without disruption to others, and to respond immediately to messages, as well as offering them the freedom to work from anywhere. These dual perspectives on mobile email (dys)functionality are explored through a metaphorical lens, showing how organisational cultures can reinforce the functional perspective while simultaneously suppressing the dysfunctional view. It is argued that it is important to understand and explore the dysfunctional perspective of mobile email adoption. The paper concludes with a series of questions that challenge organisations to reflect critically on their assumptions about mobile email usage.
\end{abstract}

\title{
Introduction
}

Email has been used in the workplace for many years (Fallows, 2002; Markus, 1994a; Sproull \& Kiesler, 1986). Short message service (SMS) and iMode provide mobile data functionality and have been popular for social communication (Barnes \& Huff, 2003; Faulkner \& Culwin, 2005; Ling, 2004; Reid \& Reid, 2004) but have not been widely adopted by the worldwide business community. Mobile email provides full access to any kind of email account by means of a portable handheld device, moving beyond the restrictions of SMS and iMode to support seamless anytime, anywhere connectivity.

In comparison to mobile telephony adoption, corporate uptake of mobile email has been slow. In the past couple of years however mobile email subscriptions have grown rapidly (Research in Motion, 2005). Analysts believe that the mobile email market will experience rapid and sustained growth in the next decade (Eazel, 2006; Malykhina, 2005), and new and established software and hardware providers like Good Technology, Microsoft, Motorola, Nokia, Palm, Research in Motion, SEVEN, Siemens, and Visto are competing intensely for market share.

In the North American context, the market leader in the mobile email sector is RIM's BlackBerry ${ }^{\circledR}$. With more than 4.3 million subscribers (Research in Motion, 2005), the BlackBerry "has become to the wireless Internet what the iPod is to music" (McKenna et al., 2006, p. B4). Through a combination of functionality (secure and reliable "push" email), design, branding, a catchy name, and celebrity endorsements (Fitchard, 2005; Gossage, 2004; McCarthy, 2005), the BlackBerry appears to have captured the imagination of consumers in North America and beyond.

Described as having a fanatical or cult-like following (Miller, 2001; Pearson, 2004; Tugend, 2004), the increasing popularity of BlackBerries has generated much press coverage. As early as 2000, Wall Street traders labelled the BlackBerry a "crackberry" (Haines, 2000). The fact that the crackberry label has become so pervasive ${ }^{1}$ reflects a strong emotional response to this mobile email device (Bing, 2005; Iley, 2004; Lill, 2004). "Addicts" deny that their dependence on the device is harmful, and enthuse about its benefits (Dudley, 2005; Fulwood III, 2005;

\footnotetext{
${ }^{1}$ The term Crackberry is now so widely used that it will have an entry in the next edition of the Oxford Canadian Dictionary: "a nickname for a BlackBerry portable e-mail device because of its addictive qualities." (Laucius, 2005)
} 
Kerr, 2005). At the same time, users' colleagues and family members find the device extremely annoying (using terms like "leashes" [Gustafson, 2004; Husted, 2004], "addictive" [Pearson, 2004] and "anti-social" [von Hahn, 2004]). In the US market, the threat of a BlackBerry shutdown led to an outpouring of fear and anxiety over the potential loss of the device (Silver \& Cherney, 2006). The government of the United States is now so reliant upon BlackBerries it declared it "imperative" that government usage of BlackBerries not be disrupted in the patent dispute that threatened this shutdown² (BlackBerry Blackout, 2005).

BlackBerry usage elicits strong reactions among users and non-users, yet a BlackBerry simply provides mobile access to email. In this paper, data on BlackBerry usage are presented as a means of exploring the opportunities and challenges of mobile email adoption. It is important to understand these issues as mobile email becomes more widely used by individuals and organisations. We adopt Robey and Boudreau's (1999) philosophy of engaging with paradox and contradiction, rather than trying to resolve it. After outlining the research method and providing a review of relevant literature, two specific research questions are addressed:

i) What are the positive and negative attributes of mobile email, and how are these reflected in its usage?

ii) How can the contradictory attitudes toward mobile email usage be understood, and what are the implications of the existence of two opposing perspectives?

The paper then adopts a critical perspective to challenge assumptions inherent in business environments that encourage a positive view of current mobile email adoption patterns. The paper outlines two perspectives on mobile email usage, demonstrating how it can be viewed as functional and dysfunctional. The paper concludes with a discussion of the implications of these findings.

\section{Research Method}

The data are drawn from interviews with 13 BlackBerry users, conducted by one of the authors in March and April 2005. Drawing on our professional networks we identified mobile email users who were invited to participate in the study. Efforts were made to achieve diversity of age, occupation, usage experience, gender and location. The 11 male and 2 female participants ${ }^{3}$ work in large Canadian cities like Montreal, Toronto, Ottawa and Regina, in a variety of industries (pharmaceuticals, information technology, insurance, construction, telecommunications, law and professional sports management). They include CEOs, entry level employees and middle management, as well as several self-employed people. Their ages range from mid-20s to mid-50s. Many of the respondents travel frequently within Canada and beyond. Their experience in using their devices ranged from less than three months to more than four years at the time of the interview.

Based on popular press descriptions of mobile email usage and informal observations of users,

\footnotetext{
${ }^{2}$ At the time of writing, RIM's patent dispute with American company NTP was unresolved, leaving open the possibility that a legal injunction would shut down BlackBerry service in the United States (Kapica, 2006; McKenna et al., 2006; Waxer, 2005). This was believed to be an unlikely outcome, and RIM assured its customers that it could deploy a work-around solution to maintain the service without violating the disputed patents.

${ }^{3}$ We acknowledge the gender imbalance among participants and intend to rectify it in future research. This analysis does not consider the impact of gender.
} 
a conceptual framework (Miles \& Huberman, 1994) was developed for the research. This framework did not set out testable hypotheses but rather identified key issues for investigation. A detailed interview protocol (available upon request) was developed to explore device functionality, mobility, and boundaries. All interviews were recorded and professionally transcribed. A coding scheme was developed based on the initial interview protocol and transcripts were coded using ATLAS.ti software.

This paper adopts a critical hermeneutics perspective. As Myers (1994, p. 189) explains:

One of the key differences between a purely interpretive approach and critical hermeneutics is that the researcher does not merely accept the self-understanding of participants, but seeks to critically evaluate the totality of understandings in a given situation.

Applying the hermeneutic circle approach of iterative data analysis, data were coded a second time to identify paradoxes and contradictions of mobile email use (using the categories outlined in the literature review), and a third time to understand how these paradoxes were interpreted by the users applying Morgan's (1997) psychic prison as the analytical lens. Data presented here come directly from the informant interviews. In some cases, quotations have been edited to improve readability, without changing the speaker's intent.

\section{Background and Literature Review}

There is a growing body of research on the nomadic work environments that are facilitated by ubiquitous computing (Kakihara \& Sørensen, 2002; Lyytinen \& Yoo, 2002; Sørensen et al., 2005; Yoo \& Lyytinen, 2005). A broad range of mobile communication technologies contribute to a nomadic environment that allows people to access a wide selection of mobile communication services. With its focus on mobile email access, this paper explores only a narrow aspect of the nomadic work environment.

Mazmanian et al. (2005) report preliminary findings of a study of mobile email users. They observe that different norms seem to apply to mobile email, with expectations of faster response times and increased availability. Users value the fact that they are constantly connected with their offices (describing this as monitoring, rather than being monitored). Concerns were noted about the usage of the devices in social settings (e.g., spouses resent the infringement on family activities), but the silent nature of mobile email allowed users to justify this behaviour as less disruptive than communication by mobile phone.

Allen and Shoard (2005) studied senior officers in a police force in the UK in order to understand how their adoption of mobile email devices impacted the problem of information overload. Mobile email usage did not reduce perceived information overload, but it did allow officers to better manage their emails by attending to them throughout the day. The use of email at home and outside normal working hours was seen as part of a usual work routine, rather than as an extension of existing work practices. Although some officers noted difficulties in shutting off their devices and stopping work, it was concluded that "the intrusion of mobile technology into users' personal lives was seen by interviewees as an acceptable trade-off for the personal productivity and flexibility benefits" (Allen \& Shoard, 2005, n.p.).

We are unaware of other published studies that focus directly on mobile email usage, but many of the positive and negative aspects of mobile telephony usage are of interest here. Mobile telephone usage is discussed by Brown, Green and Harper (2002), Haddon (1997; 2004), Katz and Aakhus (2002), Ling (2004) and Nyíri (2003), among others. The Mobile 
Phone/SMS/Instant Messaging Research (Kotamraju, 2006) and Mobile Business Literature (2006) web sites offer additional resources on mobility-related research.

By supplementing the limited existing research on mobile email usage with a broader consideration of the "dark side" of mobility (Jarvenpaa et al., 2005), we have identified four core concepts of dysfunctional usage. These concepts show that positive applications of mobile communication technologies can cross practical and social boundaries resulting in negative implications of usage.

\section{Danger}

There is clear evidence that the use of mobile telephones in vehicles causes distraction (Strayer \& Johnston, 2001). Distraction "reduces driving safety" (Johnson et al., 2004, p. 1). There is less direct evidence showing causality between in-vehicle mobile telephone use and vehicle crashes (Reinfurt et al., 2001), but a study of insurance and driving records of individuals observed using mobile phones in their cars concludes that such drivers are riskier drivers than non-phone users (Wilson et al., 2003). Although mobile phone users may attempt to mitigate the risks of phoning while driving (Pöysti et al., 2005), a review of research on this topic concludes that "using a mobile phone in a car while driving impairs driving performance significantly" (Svenson \& Patten, 2005, p. 182).

Despite the potential for danger, many drivers do use their phones in their cars (Pöysti et al., 2005). Jarvenpaa et al. (2005) discuss this in the context of a competence-incompetence paradox, suggesting that doing one thing competently (like carrying on a phone conversation) can lead to doing another thing incompetently (like driving).

\section{Anti-social Behaviour}

Ling's (2004) book includes a chapter devoted to "the intrusive nature of mobile telephony." Although individuals have different perspectives on appropriate and inappropriate mobile telephone usage, common complaints revolve around invasive, impolite and/or disruptive usage (Rosen, 2004). Invasive usage generally occurs in locations where social norms do not include the use of a mobile phone, and is an example of Jarvenpaa et al.'s public-private paradox. Impolite usage can be thought of as the problem of "absent presence" (Gergen, 2002) or "present absence" (Fortunati, 2002), where individuals stop interacting with someone they are with in person in order to interact with someone on the other end of a mobile phone. The same situation has been observed with email (Markus, 1994b) when an individual privileges an interaction with a device over a face to face interaction. Jarvenpaa et al. (2005) label this an engagement-disengagement paradox, commenting that few people can effectively engage in two tasks at the same time.

\section{Distraction}

In addition to being impolite, absent presence behaviours are also symptomatic of the disruptive nature of mobile communication technologies. Rennecker and Godwin (2005) explain how communication technologies can cause delays and interruptions in the workplace, with the observation that efforts to reduce delays by one individual result in interruptions for others. Individuals can choose to ignore or attend to a ringing phone or a beeping computer or email device, but for many, the instinctive reaction is to respond rather than to continue uninterrupted (Macklem, 2006). A study in the UK found that workers who interrupted other work to handle email as it arrived experienced "reduced mental sharpness," measured by declining IQ levels during the day (Pimentel, 2005). 


\section{Infringement}

The adoption of mobile technologies makes it difficult for some to maintain boundaries between their work and private lives (Brown \& O'Hara, 2003; Davis, 2002; Gant \& Kiesler, 2002). Jarvenpaa et al.'s empowerment-enslavement paradox recognizes the fact that anytime, anyplace connectivity can become all the time, everywhere connectivity. A mobile device can be described as a "work extension technology" (Duxbury et al., 2005), facilitating "supplemental work at home" (Duxbury et al., 1996; Venkatesh \& Vitalari, 1992). In their study of Norwegian hyttes (vacation properties), Ling et al. (1998) discuss the "paradox of discretionary communication," exploring the tensions of extending communication access to physical locations that have traditionally been sanctuaries from the reach of the telephone.

Chesley (2005) explores permeable work-life boundaries using spill-over theory, finding that mobile telephone usage is associated with negative spill-over from work to family life. In contrast, Cousins and Robey (2005) find that the four mobile workers they studied were able to successfully manage their work-life boundaries when working in a nomadic environment.

\section{Data}

These data are drawn from a secondary coding of interview transcripts and identify the paradoxes and contradictions of mobile email usage. They are categorized into the same four concepts of dysfunctional use as described above. In this section, the terms "mobile email device", "device" and "mobile" refer to respondents' BlackBerries.

\section{Danger}

Almost all of the participants in the study used their devices while driving. Two indicated that they only used the telephone, but eight admitted that they checked and/or read emails while behind the wheel (use of the device in a vehicle was not discussed in the other interviews.) Some felt that it was safer to use email than to use the phone, but 'safer' was a relative term. One user confessed, "I have almost had accidents trying to do emails while driving," adding, "I don't recommend it." Two respondents noted that their family members are concerned about their safety while driving and emailing. Another respondent developed the ability to type emails without looking at his mobile, explaining that "maybe that's because I was driving too much."

Our informants implied that using their devices in a vehicle is a bad thing to do, but noted that they mitigated the dangers of emailing while driving. "In my defence," said one user, "I usually wait until I come to a stop sign, or a light of some sort [before I check my email]." A respondent from the Canadian prairies explained "at least we don't have much traffic out here." Another noted that using his device in the car was "a lot better than what I used to do, which was talk on the phone and type on the laptop."

Users were quick to justify their in-car mobile usage. Driving time was seen as an opportunity to catch up with email, allowing users to ensure that they were not missing information while commuting. While some admitted that they read their email in the car because they were bored, the impulse to remain connected to the device was strong.

\section{Anti-social Behaviours}

Absent-present behaviours are extremely common, with twelve of thirteen respondents describing situations in which they had "abandoned" their physical surroundings to interact with someone else through their mobile. One user explained how "you can always tell" when people are not engaged in their physical environment "because their heads are down and their thumbs 
are moving." Almost everyone reported attending meetings where others were more engaged with their devices than with those in the meeting room. In some organisations, "if we are in a meeting and somebody's device buzzes or rings, nobody really notices, it's kind of like part of the culture now and everybody expects it." But in other environments, mobile email devices have been banned from meetings. Several users offered anecdotes about sending messages to colleagues in meetings, just "like passing notes in school."

Some respondents believed that people who privilege the absent over the present are indicating that "My e-mail is much more important than what you're saying to me so I'll simply be rude to you and [reply]." Others were more charitable in their assessment of this behaviour, framing it as an issue of choice, and noting that busy people may have reasons to disengage from one situation to attend to another, thereby allowing them to juggle multiple tasks at the same time. Those who did allow themselves to be accessible by email while attending to other matters emphasized that they were "just trying to productively use [their] time," and emphasized the importance of being "respectful" when using the device. For these users, the silent, unobtrusive nature of the device was very important, as was the fact that they could be responsive to multiple demands at the same time.

\section{Distraction}

Many of the people we spoke with commented on their responses to the device's distinct vibration (described as a hum or a buzz). For some, the buzzing is a "truly Pavlovian" stimulus and elicits an immediate reaction. As one user observed, "you really don't need to check every e-mail you receive, you really don't, but you feel like you should if it vibrates." Ignoring the vibrations takes practice and is a struggle for some who speak of "fighting the urge" to look at it whenever it buzzes. The devices can be set to operate in silent mode to be even more discreet, without vibrating or emitting any audible notification of the arrival of mail.

Mobile email creates frequent interruptions, but for many, the immediacy that it offers is an essential part of its value. Multitasking is a way of life for our participants, and the ability to respond quickly, from any location, to issues that arise over the course of a day is essential. With a mobile email device, users don't "miss a beat." For those who are selective about which messages are sent to their devices (users have a variety of options for managing their email), they noted that the act of giving out a device-specific email address is a way of privileging a relationship by allowing the sender direct, unmediated access to the recipient. Implicit in this exchange is an expectation of responsiveness.

\section{Infringement}

With wireless access comes infringement of boundaries. Many of our respondents reported using their devices at all hours. Several people used them as an alarm clock and noted that the first thing they did upon waking up was check their email. Others set the device to turn on and off at a specific time, reporting availability between 5 a.m. and midnight. An IT support person, whose job requires him to respond at all hours to email messages, described the device as "a leash." Many users indicated they had no formal obligation to respond to email at midnight or on weekends, but reported doing it anyway, as there is "really no excuse not to reply." One respondent said, "I've found myself on my own birthday checking emails at 10:30 at night, 11 o'clock at night." Mobile email devices facilitate the infringement of work on personal time, but for many the device simply enable pre-existing tendencies toward certain behaviours.

Many respondents used their devices at their vacation properties on weekends, or in other nonwork settings like a golf course. Several commented that they took their devices with them on 
vacation to keep in touch with their jobs. They also noted their spouses' displeasure at sharing their vacation with a mobile email device, highlighting the tensions that can occur when work spills over well beyond the office and into family time. However, these users did explain that the device itself did not create the urge to remain connected to the office on vacation, it was simply a device that made it easier to do so. As one respondent commented, "this job isn't work to me, so I don't separate work and holidays." These users were delighted that the mobile email device allowed them to read their email on the beach. Paradoxically, these behaviours were often described to demonstrate the liberating nature of mobile email, by showing how it allowed users the freedom to work anywhere.

\section{Analysis}

\section{Research Question 1}

The first research question this paper asks is, "what are the positive and negative attributes of mobile email and how are these reflected in its usage?" The data above show that each of the negative attributes identified in the general literature on mobile technology adoption is exhibited by our respondents. They provided many examples of how they used their devices, and were very mindful of the dangerous and negative behaviours associated with mobile email. But in discussing the negative attributes, positive outcomes of mobile email usage were also readily apparent.

Respondents used their devices in their cars so that they could be more efficient in dealing with the daily demands on their time. Although aware of the dangers, they chose to check their email so that they could remain in touch with their offices, colleagues or customers. Anti-social behaviours were justified because they allowed busy users to multitask with minimal perceived disruption. People couldn't physically be in two places at once, but the device allowed for virtual engagement in multiple locations. Users admitted that it was sometimes difficult to ignore their vibrating mobiles, but felt that such interruptions were warranted because they allowed for instant notification of incoming email. Being distracted from a task was a small price to pay for responsiveness. For many users, the boundaries between work and home life were breached before they started using a mobile email device. With mobile email, users had the freedom to leave the office secure in the knowledge that their email could follow them wherever they went. Although further blurring work-life boundaries, for most the device was not a leash but a liberator.

\section{Research Question 2}

The second research question asks, "How can the contradictory attitudes toward mobile email usage be understood, and what are the implications of the existence of two perspectives?" The data encompass two models of mobile email usage. One reflects negative or dysfunctional aspects, the other demonstrates a functional, beneficial perspective. The two models are illustrated in Figure 1 (the diagrams are meant to be representative, not causal, hence there are no arrows). Contradictory interpretations of specific behaviours are shown as mirror images. For example, emailing while driving is viewed as a dangerous activity in a model of dysfunctional usage, but it is seen as an efficient activity from the functional perspective. 


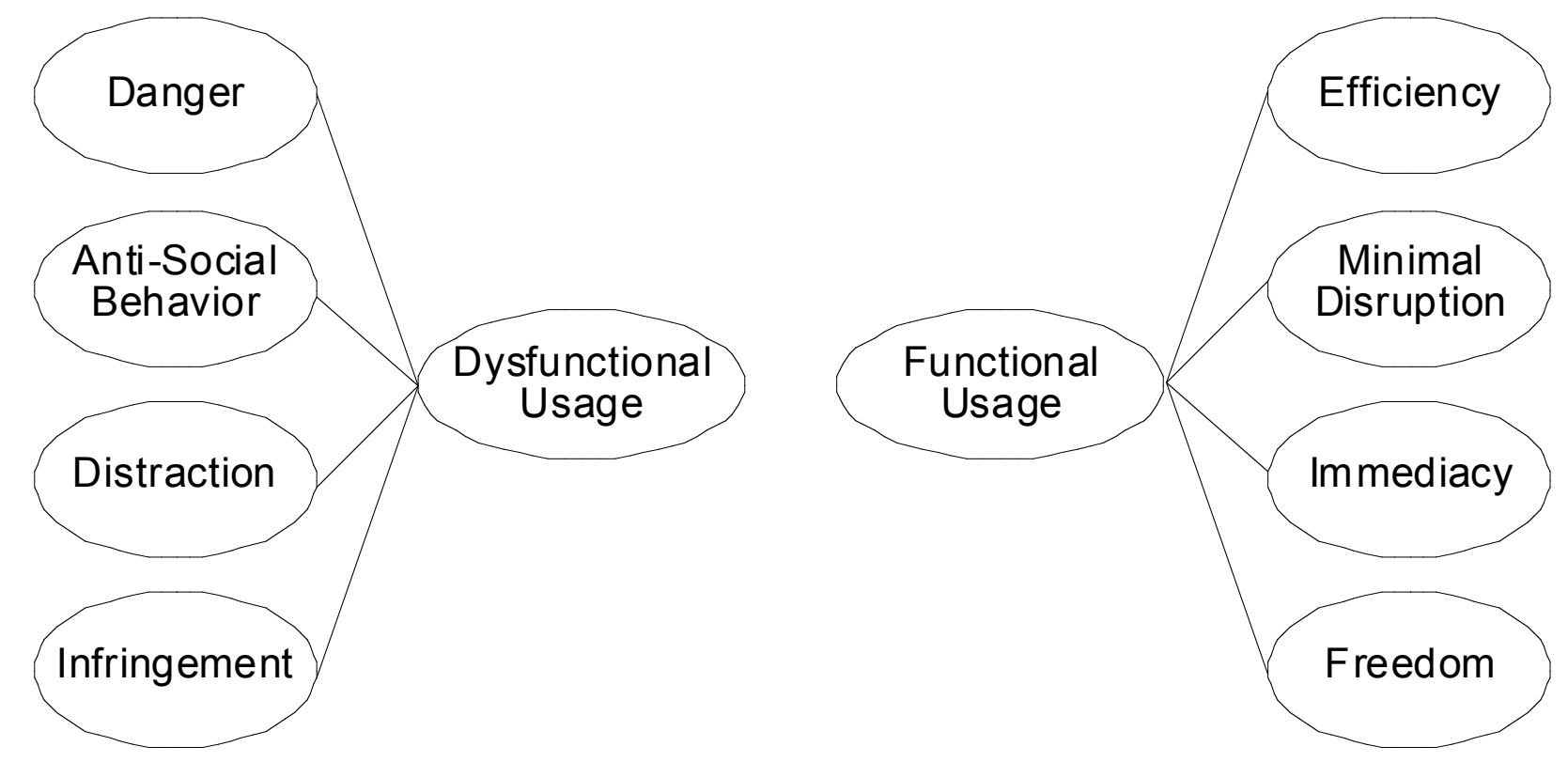

Figure 1: Contradictory Interpretations of Mobile Email Usage

This dual model of mobility can be understood through Sproull \& Kiesler's (1991) two-level perspective on technology adoption. First-level effects are "efficiency effects", and are expected to be beneficial. Second-level effects emerge over time and are felt at the system level, often producing unintended consequences and changes in social and organisational relationships. In this case, the first-level effects are seen in the functional usage model. The adoption of a mobile email device enables an individual to be more productive and efficient, thereby producing the positive impacts expected from the successful implementation of a new technology. But it is important to note that the negative, second-level dysfunctional effects of using mobile email are just as real as the functional first-level benefits. Although we did not collect data from users' colleagues, friends or families, it is evident from the users' comments that their mobile email usage does create ripples of discontent through their work and home environments.

Respondents in Jarvenpaa et al.'s (2005) study faced contradictions similar to those outlined here in their usage of mobile technologies. An analysis of those data concluded that "coping with technology paradoxes emerged as the central theme" (pp. 30-31). In contrast, our data suggest that although users easily identified the paradoxes of mobile email, they were not conflicted by them or especially concerned about establishing coping behaviours. Instead, our respondents used an "end justifies the means" reasoning to explain why they found their devices so useful. They did not dwell on their dysfunctional aspects. At an individual level, this instrumental focus on the benefits can be a successful approach. The respondents explained clearly how their devices helped them to manage their busy lives, acknowledging only limited negative consequences. But Sproull and Kiesler (1991) observe that "early in the life of a new technology, people are likely to emphasize the efficiency effects" (p. 15), while noting that the second-level effects are more important for organisations in the longer term. To conclude this paper, we offer a critical interpretation of our data. We offer an explanation as to why users are not concerned about the second-level effects of mobile email usage and we raise questions that organisations should address in order to manage the second-level effects. 


\section{A Critical Interpretation}

Consistent with the critical hermeneutical frame employed in this research, our analysis now shifts beyond respondents' interpretations of their mobile email usage. Following Robey and Boudreau (1999), we apply the lens of organisational culture to seek an explanation for the contradictory understandings of mobile email. As has been noted, users believe that anytime, anywhere mobile email enables high functionality in stressful and busy work environments. In contrast, the assessment of dysfunctional usage appears to originate outside the user environment. Both interpretations are supported by the data. While users rationalize their always-connected lifestyle, we suggest that the legitimacy of this rationalization can, and should, be challenged.

Morgan (1997) argues for the use of metaphor in analysing organisations. He shows how organisational cultures can reinforce positive attitudes and activities in organisations, as well as create friction and dissonance. One negative manifestation of culture is the 'psychic prison.' In a psychic prison, organisations or individuals can become "trapped by constructions of reality that, at best, give an imperfect grasp on the world" (p. 216). People become imprisoned by their ideas, sharing myopic mindsets and blocking alternative perspectives or interpretations of events and actions. Defence mechanisms like denial, repression, fixation and rationalization reinforce this shared mindset. We suggest that the psychic prison metaphor offers insights into the contradictory interpretations of mobile email usage presented above.

As discussed earlier, our respondents frequently rationalized their mobile email behaviours. They described their devices as "liberating," providing "peace of mind," "reassurance" and "control." Others explained that the device "works for me," or that using it was the cost of doing business, a necessity for the demands of the job. The device was there "just in case," because others are reliant on its users.

Users were strongly committed to their patterns of use, showing evidence of fixation and compulsion. They used their devices on bicycles, in cars, airplanes, trains, taxis and buses, at all times of day and night. They used them while on vacation (rationalizing this behaviour as a way of staying in touch) and took them to the beach and to the park. They used them in meetings, while on the telephone and when watching television. When the device "buzzed," many users could not resist the urge to immediately check the new email message it signalled.

Our respondents' frequent rationalizations about their mobile email usage and their fixations about constantly checking and responding to messages received on their devices illuminate their common perspective on what mobile email is for and what accepted usage patterns are. It is well-understood that using a mobile email device provides a level of access and immediacy to business communication that does not occur so easily in other forms of communication. It is recognized that usage of mobile email devices can change expectations regarding availability and responsiveness. These expectations are accepted as part of the culture of mobile email use, a culture that is shaped by users' organisational and institutional environments.

Returning to Morgan's (1997) psychic prison metaphor, we argue that there is a shared mindset among mobile email users, one that promotes the functional interpretation of mobile email and suppresses the dysfunctional interpretation. Morgan uses the example of Plato's cave to argue that the interpretation of a phenomenon as perceived from within a specific environment can be very different from the interpretation of the same phenomenon from an external perspective. In Plato's cave, people chained to the cave wall with their backs to the light perceive that images cast on the cave wall are not shadows of themselves, but are actual beings with whom they 
interact. Extending this metaphor to the organisational adoption of mobile email, picture the mobile email user inside such a cave. The "outside" environment is reflected inward, so that behaviours that are seen as dysfunctional in the external environment are cast in a functional light in the internal environment. This is illustrated in Figure 2.

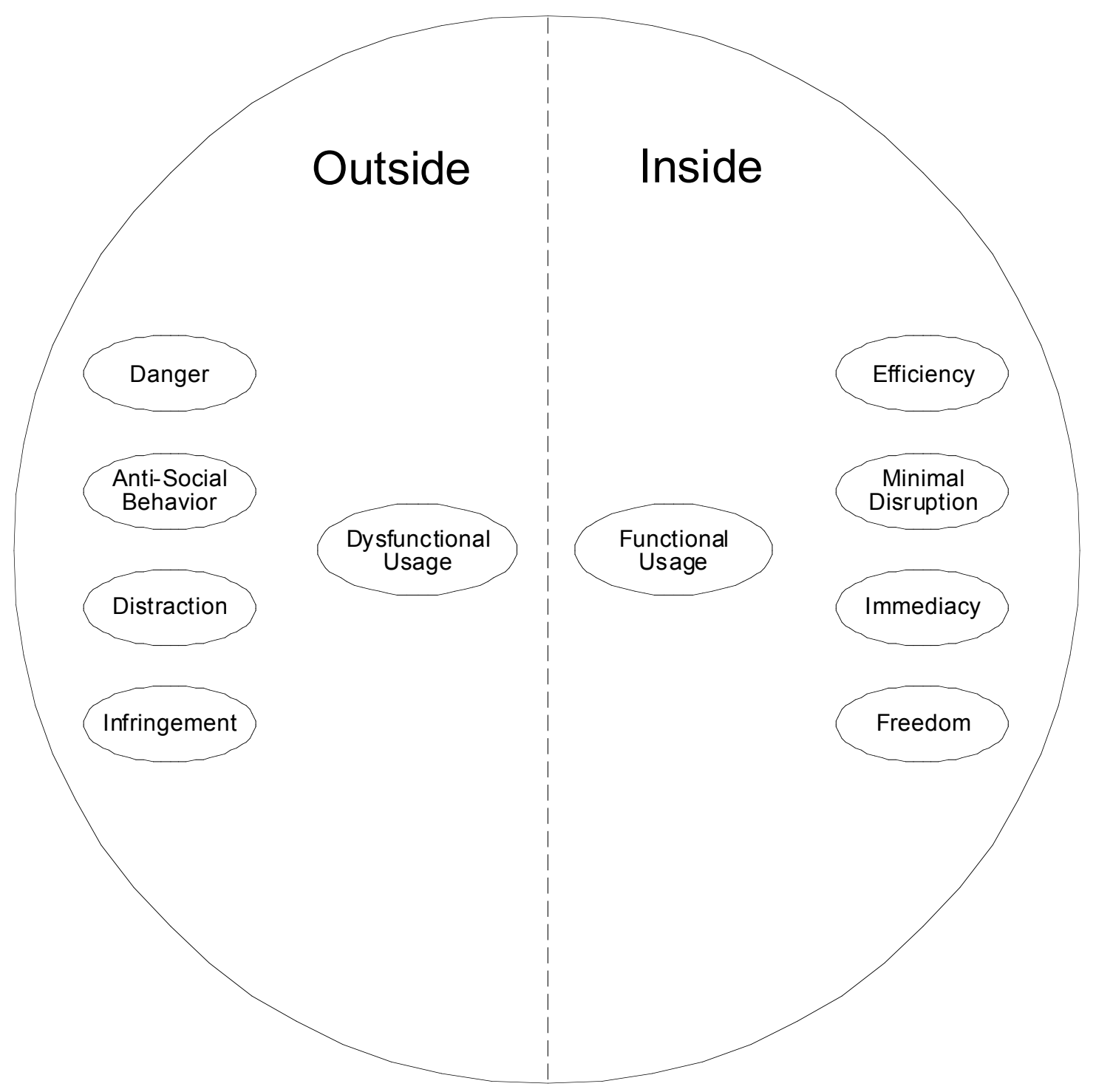

Figure 2: The Psychic Prison: Perceptions of Mobile Email Usage Inside and Outside
Plato's Cave

This metaphor offers a mechanism through which to challenge the mindset of mobile email users who can be seen as trapped within the "functional usage" perspective. Everyone inside Plato's cave shares the same vision of reality, but it is a vastly different one from those on the outside. The first-order effects of mobile email usage are seen within the cave, while the second-order effects are manifest in the external environment.

\section{Discussion and Conclusions}

While the data in this paper report usage of a particularly seductive mobile email device (the 
BlackBerry), we believe our findings are not device-specific. Recognizing this, and anticipating growth in mobile email adoption, the implications for individuals and organisations of a mindset that constructs mobile email usage as highly functional must be identified and addressed.

This functionality mindset has not been created by users alone but reflects broader beliefs and attitudes in the business environment. Connectedness is seen to be an asset, and in a competitive business environment businesses are encouraged to provide mobile email access throughout their organisations. But it is important to consider whether this business-centric perspective is the appropriate guiding vision for future mobile email usage. Who should define what is "appropriate" in the context of mobile email? Can a mindset be developed that reflects the needs and concerns of businesses, employees, and others with whom they interact? More specifically, how can organisations encourage patterns of use or policies that respect social boundaries, while balancing organisational and personal needs? How can the norms and expectations for mobile email be developed in ways that address the current paradoxes of functional and dysfunctional usage? How are issues of power and gender reflected in the development of future norms? How can the norms for usage of mobile email reflect and accommodate different global business cultures?

Situating mobile email users within Plato's cave implies a clear distinction between behaviours that are acceptable inside the cave and those that are acceptable outside the cave. As mobile email is more widely adopted, it is important to consider how the boundary between inside and outside views of acceptable practices can be delineated or defined and rules of tolerance established. While some people would argue that the norms of mobile email usage as developed "within the cave" are perfectly acceptable (see Ferrazzi, 2005, for example) we disagree. We understand that users believe their behaviours are justified and we recognize that such behaviours are a reflection of the business environments in which they exist. Nevertheless, we encourage people to challenge assumptions about necessary work practices, including the perceived need to be available anytime, anywhere. For example,

- Do people really need to be checking their email on the beach or while driving?

- Is it sensible behaviour to jump out of bed in the morning and immediately check email?

- Should people be so connected to their offices and work that they feel they must take their mobile devices with them on vacation, or to the doctor's office?

- Is it absolutely necessary to work all the time, filling in "dead" time by writing emails in planes and taxis?

- Is it realistic to try to be in two or more places at once, managing communication with multiple parties through mobile email?

In summary, how do we distinguish the work practices that are necessary from those that are dangerous, infringe upon personal space and time, disrupt work flow, or are anti-social?

These questions are prompted by this study of mobile email users, but the answers do not rest in the technology. The technological behaviours reported here describe or diagnose an organisational culture. While the availability of mobile email allows individuals to survive within a culture that compromises boundaries in the name of anytime, anywhere responsiveness, mobile email usage simultaneously enables and perpetuates this culture.

The psychic prison metaphor allows an evaluation of this culture, asking whether this specific construction of reality might be flawed. We offer an alternative perspective, showing how current mobile email usage patterns have become embedded in their users' lives in 
dysfunctional ways. This paper has provided an in-depth look at mobile email usage patterns, drawing on the experiences of BlackBerry users. While their behaviours can be seen as extreme, they reflect a business environment in which mobile email has become a central feature. In this environment, dysfunctional elements of mobile email usage are ignored, in favour of a functional perspective that results in people being available anytime, anywhere. While mobile email has much to offer, we suggest that its potential for dysfunctional usage should be recognized and addressed in order to create a better working environment for all.

\section{Acknowledgements}

This research was funded by the Social Sciences and Humanities Research Council of Canada. We wish to thank the guest editors, anonymous reviewers and our colleague Ojelanki Ngwenyama for their assistance in revising this paper. Eva Woyzbun provided editorial support. 


\section{References}

ALLEN DK and SHOARD M (2005) Spreading the load: Mobile information and communications technologies and their effect on information overload. Information Research 10(2, Paper 227), non-paginated.

BARNES SJ and HUFF SL (2003) Rising sun: iMode and the wireless internet. Communications of the ACM 46(11), 78-84.

BING S (2005) Bye-bye, BlackBerry. Fortune,151(1), p 102.

BLACKBERRY BLACKOUT (2005: 30 November) Wall Street Journal, New York, p A18.

BROWN B, GREEN N and HARPER R (Eds.) (2002) Wireless world: Social and interactional aspects of the mobile age. Springer-Verlag, London.

BROWN B and O'HARA K (2003) Place as a practical concern of mobile workers. Environment and Planning A 35(9), 1565-1587.

CHESLEY N (2005) Blurring boundaries? Linking technology use, spillover, individual distress, and family satisfaction. Journal of Marriage and Family 67(5), 1237-1248.

COUSINS KC and ROBEY D (2005) Human agency in a wireless world: Patterns of technology use in nomadic computing environments. Information and Organization 15(2), 151-180.

DAVIS GB (2002) Anytime/anyplace computing and the future of knowledge work. Association for Computing Machinery. Communications of the ACM 45(12), 67-73.

DUDLEY J (2005: 17 December) Electric avenue. Courier-Mail, Brisbane, p 26.

DUXBURY L, THOMAS JA, TOWERS I and HIGGINS C (2005) From 9 to 5 to 24 and 7: How technology has redefined the workday. Unpublished report prepared for Industry Canada. Ottawa.

DUXBURY LE, HIGGINS CA and THOMAS DR (1996) Work and family environments and the adoption of computer-supported supplemental work-at-home. Journal of Vocational Behavior 49(1), 1-23.

EAZEL W (2006) Mobile email set to explode. http://www.vnunet.com/actions/trackback/2149865. Accessed: 14 February, 2006.

FALLOWS D (2002) Email at work: Few feel overwhelmed and most are pleased with how email helps them do their work. Pew Internet and American Life Project, Washington, DC, pp $1-26$.

FAULKNER X and CULWIN $F$ (2005) When fingers do the talking: A study of text messaging. Interacting with Computers 17(2), 167-185.

FERRAZZI K (2005) Why "Balance" Is B.S. Chief Executive (211), 28.

FITCHARD K (2005) Pushing e-mail. Wireless Review 22(8), 20-22.

FORTUNATI $L$ (2002) The mobile phone: Towards new categories and social relations. Information, Communication \& Society 5(4), 513-528.

FULWOOD III S (2005: 8 December) First of 12 steps toward berry-free. Plain Dealer, Cleveland, p B1. 
GANT D and KIESLER S (2002) Blurring the boundaries: Cell phones, mobility and the line between work and personal life. In Wireless world: Social and interactional aspects of the mobile age (BROWN B, GREEN N and HARPER R, Eds), pp 121-131, Springer-Verlag, London.

GERGEN KJ (2002) The challenge of absent presence. In Perpetual contact: Mobile communication, private talk, public performance (KATZ JE and AAKHUS MA, Eds), pp 227-241, Cambridge University Press, Cambridge, MA.

GOSSAGE B (2004) What's in a name? http://pf.inc.com/magazine/20040701/gettingstarted.html. Accessed: 15 January, 2006.

GUSTAFSON KI (2004: 18 October) 'sounds like a plan'. Times Union, Albany, NY, p C1.

HADDON L (Ed.) (1997) Communications on the move: The experience of mobile telephony in the 1990s. CULCOM, Brighton, Sussex.

HADDON L (2004) Information and communication technologies in everyday life. Berg, Oxford.

HAINES M (2000: 29 September) Research in Motion - CFO - interview: Transcript. CNBC/Dow Jones Business Video.

HUSTED B (2004: 8 April) Electronic leash steals our time for contemplation. Dayton Daily News, Dayton, p E3.

ILEY C (2004: 7 November) Curse of the 'crackberry'. The Sunday Times, London, p Style 19.

JARVENPAA SL, LANG KR and TUUNAINEN VK (2005) Friend or foe? The ambivalent relationship between mobile technology and its users. In Designing ubiquitous information environments: Socio-technical issues and challenges (SØRENSEN C, YOO Y, LYYTINEN K and DeGross JI, Eds), pp 29-42, Springer, New York.

JOHNSON MB, VOAS RB, LACEY JH, MCKNIGHT AS and LANGE JE (2004) Living dangerously: Driver distraction at high speed. Traffic Injury Prevention 5(1), 1-7.

KAKIHARA M and SøRENSEN C (2002) Mobility: An extended perspective. In Proceedings of the 35th Annual Hawaii International Conference on System Sciences, pp 1756- 1766.

KAPICA J (2006: 11 January) RIM versus NTP. Globe and Mail, Toronto.

KATZ JE and AAKHUS MA (2002) Perpetual contact: Mobile communication, private talk, public performance. Cambridge University Press, Cambridge.

KERR J-L (2005: 10 December) BlackBerry fans cringe at talk of a disconnect. The Florida Times-Union, Jacksonville.

KOTAMRAJU NP (2006) Mobile phone/SMS/instant messaging research. http://istsocrates.berkeley.edu/ nalinik/mobile.html. Accessed: 30 January, 2006.

LAUCIUS J (2005: 16 December) Infomaniacs, ubersexuals now have home in dictionary. The Ottawa Citizen, Ottawa, p A7.

LILL C (2004) Vodafone imports the infamous BlackBerry. National Business Review.

LING R, JULSRUD T and KROGH E (1998) The goretex principle: The hytte and mobile telephones in Norway. In Communications on the move: The experience of mobile telephony in the 1990s, COST248 report (HADDON L, Ed), pp 97-120, Telia AB, Farsta.

LING RS (2004) The mobile connection: The cell phone's impact on society. Morgan Kaufmann, 
San Francisco, CA.

LYYTINEN K and YOO Y (2002) Research commentary: The next wave of nomadic computing. Information Systems Research 13(4), 377-388.

MACKLEM K (2006) You've got too much mail. Macleans,119(5), pp 20-21.

MALYKHINA E (2005) Everyone wants one -- demand for BlackBerrys and similar devices is growing even faster than anticipated. But as mobile e-mail booms, so do the challenges. InformationWeek,1069, p 24.

MARKUS ML (1994a) Electronic mail as the medium of managerial choice. Organization Science 5(4), 502-527.

MARKUS ML (1994b) Finding a happy medium: Explaining the negative effects of electronic communication on social life at work. ACM Transactions on Information Systems 12(2), 119-149.

MAZMANIAN MA, ORLIKOWSKI WJ and YATES J (2005) Crackberries: The social implications of ubiquitous wireless e-mail devices. In Designing ubiquitous information environments: Socio-technical issues and challenges (SØRENSEN C, YOO Y, LYYTINEN K and DeGross JI, Eds), pp 337-344, Springer, New York.

MCCARTHY S (2005: 25 November) Oprah's magic, BlackBerry's hope: RIM hoping plug on star's TV show translates into sales. The Globe and Mail, Toronto, p B1.

MCKENNA B, WALDIE P and AVERY S (2006: 28 January) Patently absurd. Globe and Mail, Toronto, pp B4-5.

MILES M and HUBERMAN AM (1994) Qualitative data analysis: An expanded sourcebook. Sage, Thousand Oaks, CA.

MILLER H (2001: 25 January) Get ready for a pager on steroids. The Guardian, p 7.

MOBILE BUSINESS LITERATURE (2006) http://www.m-lit.org/default.asp. Accessed: 30 January, 2006.

MORGAN G (1997) Images of organization. Sage, Thousand Oaks, CA.

MYERS MD (1994) A disaster for everyone to see: An interpretive analysis of a failed IS project. Accounting, Management and Information Technologies 4(4), 185-201.

NYÍRI K (2003) Mobile democracy: Essays on society, self and politics. Passagen Verlag, Vienna.

PEARSON B (2005: 12 February) Get your thumb on the pulse BlackBerry infamous as the tool of embarrassment for Alastair Campbell, the latest must-have accessory is too much for some. The Herald, Glasgow, p 17.

PEARSON M (2004: 17 July) BlackBerry 'addicts' need their connection. Rocky Mountain News, Denver, $\mathrm{p} 2 \mathrm{D}$.

PIMENTEL B (2005: 4 May) E-mail addles the mind: Endless messaging rots brain worse than pot, study finds. San Francisco Chronicle, San Francisco, p C1.

PÖYSTI L, RAJALIN S and SUMMALA H (2005) Factors influencing the use of cellular (mobile) phone during driving and hazards while using it. Accident Analysis and Prevention 37(1), 47-51.

REID D and REID F (2004) Insights into the social and psychological effects of SMS text 
messaging. University of Plymouth Working Paper, Plymouth, UK.

REINFURT DW, HUANG HF, FEAGANES JR and HUNTER WW (2001) Cell phone use while driving in North Carolina. University of North Carolina Highway Safety Research Center, Chapel Hill, NC.

RENNECKER J and GODWIN L (2005) Delays and interruptions: A self-perpetuating paradox of communication technology use. Information and Organization 15(3), 247-266.

RESEARCH IN MOTION (2005) Research in Motion reports third quarter results. http://www.rim.com/news/press/2005/pr-21 12 2005-01.shtml. Accessed: 23 January, 2006.

ROBEY D and BOUDREAU M-C (1999) Accounting for the contradictory organizational consequences of information technology: Theoretical directions and methodological implications. Information Systems Research 10(2), 167-185.

ROSEN C (2004) Our cell phones, ourselves. The New Atlantis Summer, 26-45.

SILVER S and CHERNEY E (2006: 12 January) Bye-bye blackberrys? Competitors are launching new wireless email devices as patent concerns linger. Wall Street Journal, New York, p D1.

SØRENSEN C, YOO Y, LYYTINEN K and DeGross JI (2005) Designing ubiquitous information environments: Socio-technical issues and challenges. Springer, New York.

SPROULL L and KIESLER S (1986) Reducing social context cues: Electronic mail in organizational communication. MS 32(11), 1492-1512.

SPROULL LS and KIESLER SB (1991) Connections - new ways of working in the networked organization. MIT Press, Cambridge, MA.

STRAYER DL and JOHNSTON WA (2001) Driven to distraction: Dual-task studies of simulated driving and conversing on a cellular telephone. Psychological Science 12(6), 462-466.

SVENSON O and PATTEN CJD (2005) Mobile phones and driving: A review of contemporary research. Cognition, Technology and Work 7(3), 182-197.

TUGEND A (2004) Blackberry jam. http://www.govexec.com/features/1104-01/1104-01s2.htm. Accessed: 14 February, 2005.

VENKATESH A and VITALARI NP (1992) An emerging distributed work arrangement: An investigation of computer-based supplemental work at home. Management Science 38(12), 1687-1706.

VON HAHN K (2004: 1 May) I'm a blackberry widow. Globe and Mail, Toronto, p L3.

WAXER C (2005) BlackBerry against The world. Chief Executive (212), 38-41.

WILSON J, FANG M, WIGGINS S and COOPER P (2003) Collision and violation involvement of drivers who use cellular telephones. Traffic Injury Prevention 4(1), 45 - 52.

YOO Y and LYYTINEN K (2005) Social impacts of ubiquitous computing: Exploring critical interactions between mobility, context and technology: A special issue for information and organization. Information and Organization 15(2), 91-94. 